Jurnal Sain Veteriner, Vol. 37. No. 1. Juni 2019, Hal. 104-111

DOI : $10.22146 /$ jsv.42944

ISSN 0126-0421 (Print), ISSN 2407-3733 (Online)

Tersedia online di https://jurnal.ugm.ac.id/jsv

\title{
Evaluasi Pengobatan Trematodiasis Menggunakan Albendazol pada Sapi di Kecamatan Pakem, Sleman, Daerah Istimewa Yogyakarta
}

\author{
The Evaluation of Albendazole Therapy for Trematodiasis in Cattle \\ at Pakem District, Sleman, Daerah Istimewa Yogyakarta
}

\author{
Felisitas Kristiyani ${ }^{1}$, Nurul Aini ${ }^{1}$, Agustina Dwi Wijayanti ${ }^{2^{*}}$ \\ ${ }^{1}$ Pusat Kesehatan Hewan Pakem, Dinas Pertanian, Pangan dan Perikanan Kabupaten Sleman \\ ${ }^{2}$ Departemen Farmakologi, Fakultas Kedokteran Hewan, Universitas Gadjah Mada \\ Jl. Fauna No. 2 Karangmalang, Yogyakarta 55281 \\ *Email : tinabudiyanto@yahoo.co.id
}

Naskah diterima : 23 Januari 2019, direvisi : 15 Februari 2019, disetujui : 15 Mei 2019

\begin{abstract}
The recent method of treatment for trematodiasis in cattle (age 1-10 years) using albendazol (10\% of orally suspension) has deducted to evaluate the effectiveness of this anthelmintic to eradicate the trematoda infection especially Fasciola sp. and Paramphistomum sp. in Pakem subdistrict, Sleman district, Daerah Istimewa Yogyakarta Provence. These two species of trematodes were the mostly found in Yogyakarta area according to the annualy reports of Idul Qurban slaughter day. The cows used in this study were determined from three groups of farmers society at Pakem area. The physical examination and feces samplings for worm egg identification by Parfitt and Banks method were done as early examination to all populations. The positive results of Fasciola sp. and Paramphistomum sp. eggs of cows then grouped (Group A,B, and C) and treated with albendazole at dose of $10 \mathrm{mg} / \mathrm{kg}$ of body weight. All groups treated countinously for one year with albendazole; Group A repeated every two months, group B every four months, and group $\mathrm{C}$ every six months, respectively. Before administered the next dosing, the feces samplings and worm eggs identification were conducted to measure the effectiveness of albendazole that had applied. The results of treatments were the finding of trematoda eggs in feces then calculated descriptively. The effectiveness of albendazol of two months repetition was $31,25-100 \%$, every four months was $38,47-46,15 \%$ and six months repeatly was $42,86 \%$. It concluded that the highest effectiveness of albendazol to trematodiasis in cattle was two months repetition of treatment. The evaluation of albendazole treatments of cattle infected by Fasciola sp. and Paramphistomum sp. during 12 months resulted the low effectiveness because of only $30 \%$ of population that cured from infections.
\end{abstract}

Keywords: albendazole; cattle; effectiveness; Fasciola sp.; Paramphistomum sp.

\begin{abstract}
Abstrak
Penelitian metode pengobatan trematodiasis pada sapi dewasa (umur 1-10 tahun) menggunakan albendazol (sediaan suspensi oral 10\%) dilakukan untuk mengetahui metode terapi yang paling efektif terhadap infestasi cacing yang sering terjadi pada ternak sapi di Indonesia, khususnya di wilayah Sleman, Daerah Istimewa Yogyakarta. Infestasi cacing trematoda terutama Fasciola sp. dan Paramphistomum sp. cukup sering ditemukan di wilayah ini, dan sering ditemukan saat pemeriksaan tahunan penyembelihan hewan pada perayaan Idul Qurban. Sampel yang digunakan adalah sapi-sapi yang dipelihara di 3 kelompok ternak ( kelompok A, B, dan C) di wilayah Kecamatan Pakem, Kabupaten Sleman. Pemeriksaan fisik dan feses untuk identifikasi telur cacing dilakukan terhadap seluruh populasi di ketiga kelompok. Pengobatan yang dilakukan adalah dengan albendazol dosis $10 \mathrm{mg} / \mathrm{kg}$ berat badan, dengan metode ulangan untuk Kelompok A setiap 2 bulan sekali, Kelompok B tiap 4 bulan sekali dan kelompok C tiap 6 bulan sekali, selama satu tahun. Pemilihan sampel untuk pengamatan efektifitas obat cacing ditentukan pada sapi yang positif terinfeksi pada pemeriksaan pertama dengan ditemukan telur Fasciola $s p$. dan Paramphistomum $s p$. menggunakan metode Parfitt and Banks. Sebelum ulangan pengobatan, dilakukan pemeriksaan feses untuk mengukur efektivitas pengobatan sebelumnya. Berdasarkan data diketahui bahwa pengobatan albendazol dengan ulangan 2 bulan memberikan efektivitas berkisar 31,25-100\%, ulangan 4 bulan 38,47-46,16\% dan ulangan 6 bulan menghasilkan efektivitas sebesar $42,86 \%$. Berdasarkan data tersebut disimpulkan bahwa efektivitas pengobatan menggunakan albendazol tertinggi diperoleh dengan cara mengulang pengobatan setiap 2 bulan sekali. Evaluasi terhadap seluruh populasi sapi yang terinfeksi Fasciola sp. dan Paramphistomum sp. selama 12 bulan menunjukkan rendahnya
\end{abstract}


efektivitas albendazol karena hanya mampu menjaga ternak sapi dari infeksi kurang dari $30 \%$ populasi.

Kata kunci : albendazol; efektivitas; Fasciola sp.; Paramphistomum sp.; sapi,

\section{Pendahuluan}

Kasus penyakit cacingan (helmintiasis) pada ternak di Indonesia cukup tinggi. Di wilayah Sleman, Daerah Istimewa Yogyakarta, kasus cacingan pada sapi mulai tahun 2013 hingga 2017 selalu dilaporkan tinggi terutama saat disembelih pada Hari Raya Kurban oleh para petugas pemeriksa daging kurban. Cacing yang menginfeksi ternak di daerah Sleman terutama adalah jenis Fasciola sp. dan Paramphistomum sp., meskipun jenis lain juga ditemukan. Fasciola hepatica sering menginfeksi di daerah beriklim sedang, sedangkan Fasciola gigantica umumnya di daerah beriklim tropis basah (Kaplan, 2001). Terkait dengan tingginya kasus cacingan maka pengobatan dengan obat cacing (antelmintika) merupakan salah satu pengendalian yang paling efektif, selain juga harus dilakukan perbaikan menajemen pemeliharaan ternak, terutama yang terkait dengan masalah pakan yang berkualitas dan sanitasi. Helmintiasis menyebabkan kerugian yang berdampak luas pada ternak dan manusia (Colley et al., 2001).

Infeksi cacing pada ruminansia disebabkan oleh berbagai golongan cacing gastrointestinal. Pada umumnya infeksi cacing ruminansia disebabkan oleh golongan nematoda (Ostertagia sp., Capillariasp., Trichuris sp., Strongyliodes sp.), cestoda (Moniezia sp., Taenia sp.) dan trematoda (Dicrocoelium sp., Fasciola gigantica, Amphistomes) (Zahid et al., 2005) ). Menurut Regassa et. al.(2006), kerugian ekonomi akibat infeksi parasit gastrointestinal pada ruminansia adalah turunnya produktivitas meliputi turunnya produksi susu, angka fertilitas rendah, penurunan tenaga ternak pekerja, tingginya culling, tingginya biaya pengobatan dan turunnya harga jual.

Salah satu obat cacing berspektrum luas yang banyak digunakan di Indonesia adalah golongan albendazol. Jenis obat cacing ini banyak digunakan karena efektivitasnya terhadap banyak golongan parasit gastrointestinal, serta memiliki harga yang terjangkau di negara berkembang. Obat ini juga terdaftar dalam daftar World Health Organization (WHO) list of essential Medicine, sebagai obat yang efektif dan aman (WHO, 2016). Namun beberapa penelitian dan laporan studi menunjukkan adanya resistensi terhadap penggunaan beberapa obat cacing termasuk albendazol di negara berkembang maupun di negara maju (Jaeger and Costa, 2017; Ramos et al.,2016, dan Waghorn et al.,2006). Golongan Benzimidazol, misalnya albendazol dan fenbendazol, memiliki spektrum aktivitas yang luas dan digunakan di seluruh dunia ( De Graef etal., 2013; Yazwinski etal., 2009; Cezar etal., 2010). Demeler etal. (2009) melaporkan efektivitasnya pada hewan besar lebih dari 95\% . Namun penelitian selanjutnya oleh Ramos et al.(2016) menunjukkan efektivitas albendazol turun kurang dari 90\% pada beberapa peternakan di Brazil, dan fenbendazol hanya memiliki efektivitas yang tinggi pada dua peternakan. Menurut penelitian tersebut, diperkirakan penggunaan golongan benzimidazol yang terlalu sering sebagai agen antiparasit merupakan pemicu terjadinya resistensi.

Data yang diperoleh dari program pengobatan cacing di beberapa kelompok peternakan sapi di wilayah Kabupaten Sleman menunjukkan beragam respon efektivitas albendazol berdasarkan jangka waktu pemberiannya, namun belum ada data yang diolah sehingga diperoleh kesimpulan seberapa besar efektivitas albendazol dalam mengobati cacingan di 
Felisitas et. al.

wilayah Sleman. Perkembangan efektivitas albendazol sebagai antelmintika pada ternak di wilayah kabupaten Sleman dalam waktu beberapa tahun ini belum pernah dilaporkan sebelumnya. Studi tentang efektivitas albendazol pada sapi ini dilakukan untuk melihat perbedaan efektivitas pengobatan cacing Fasciola sp. dan Paramphistomum sp. menggunakan albendazol yang diberikan dalam jangka waktu 2 bulan, 4 bulan dan 6 bulan dalam waktu 12 bulan (1 tahun).

\section{Materi dan Metode}

Penelitian menggunakan 3 kelompok ternak sapi potong (umur sapi berkisar 1 sampai 10 tahun, jantan dan betina) di kecamatan Pakem, Kabupaten Sleman, Daerah Istimewa Yogyakarta. Total jumlah sapi yang terinfentasi golongan Fasciola sp., dan Paramphistomum sp. pada pemeriksaan awal adalah 52 ekor. Infestasi cacing ditetapkan berdasarkan pemeriksaan feses sapi menggunakan metode Parfitt and Banks untuk mengidentifikasi jenis telur cacing Fasciola sp.dan Paramphistomum sp. (Parfitt and Banks, 1970). Prinsip uji ini adalah pengendapan, yaitu 3 gram feses dengan aquades dicampur dan digerus dengan mortir, selanjutnya dimasukkan ke dalam tabung reaksi hingga $1 \mathrm{~cm}$ dari mulut tabung, dan didiamkan selama 10 menit. Cairan diambil dengan pipet sehingga tinggal endapan di dasar tabung. Selanjutnya ditambah aquades lagi hingga 1 cm dari mulut tabung, dikocok dan didiamkan 10 menit. Cairan dibuang, selanjutnya ditambah larutan $\mathrm{NaOH} 10 \% 3$ tetes dan ditambah aquades lagi hingga berjarak $1 \mathrm{~cm}$ dari mulut tabung, dikocok dan didiamkan 10 menit. Selanjutnya cairan jernih dibuang, ditambah 3 tetes methylene blue, diaduk, dan endapan paling bawah diambil, ditaruh dalam obyek glass dan diperiksa di bawah mikroskop dengan perbesaran 10x10. Telur Fasciola sp. tampak kekuningan karena tidak menyerap methylene blue, dan telur Paramphistomum sp. berwarna hijau kebiruan. Sapi-sapi yang terdeteksi positif telur cacing Fasciola sp. dan atau Paramphistomum sp. selanjutnya diberi albendazol ( suspensi 10\%) per oral dengan dosis $10 \mathrm{mg} / \mathrm{kg}$ berat badan atau $1 \mathrm{~mL} / 10 \mathrm{~kg}$ berat badan. Kelompok A (22 ekor sapi) diberi albendazol dengan ulangan tiap 2 bulan, kelompok B (19 ekor sapi) dengan ulangan tiap 4 bulan dan kelompok C (11 ekor sapi) dengan ulangan tiap 6 bulan. Pengelompokkan sapi dan pemberian perlakuan ulangan obat ( A, B, C ) didasarkan atas wilayah kelompok ternak untuk menghindari terjadinya reinfestasi cacing akibat pengulangan pemberian obat yang tidak seragam dalam satu kelompok. Hari pertama pemberian obat disebut sebagai pengulangan ke- 0 dan periode pengulangan selanjutnya disebut pengulangan ke-1, 2, 3, dan seterusnya. Sebelum dilakukan pengulangan pemberian obat pada periode berikutnya, dilakukan pemeriksaan feses terlebih dahulu, dan pemberian ulangan obat tetap dilakukan meskipun pemeriksaan feses tidak ditemukan telur cacing (negatif). Efektivitas atau kesembuhan dinyatakan apabila tidak ditemukan telur cacing pada feses. Pengobatan dilakukan selama 12 bulan dan data yang diperoleh selanjutnya dianalisis secara deskriptif.

\section{Hasil dan Pembahasan}

Hasil identifikasi telur Fasciola sp. ( Gambar 1) terlihat bentuk ovoid, tidak bersegmen dan berwarna kekuningan karena tidak menyerap zat warna methylene blue. Data pemeriksaan feses setiap periode pengobatan dengan albendazol terhadap sapi yang terinfeksi Fasciola sp. dan Paramphistomum sp. dapat dilihat pada Tabel 1,2 dan 3 . 


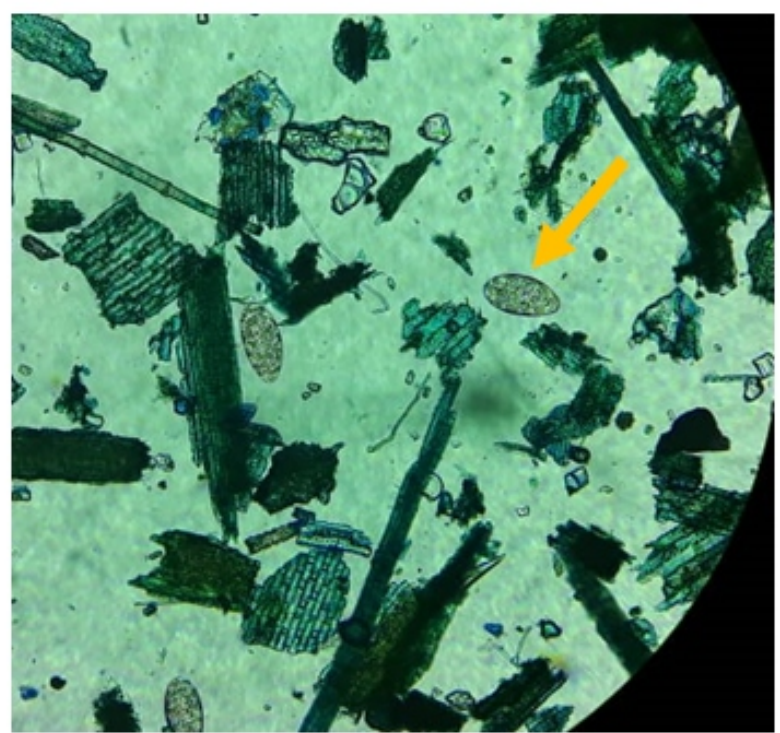

Gambar 1. Mortologi telur Fasciola sp. (tanda panah, perbesaran 10x10)

Pengobatan albendazol ulangan 2 bulan memberikan nilai efektivitas ( nilai kesembuhan) yang fluktuatif berkisar antara 36,36 - 100\%. Efektivitas terus naik mulai dari ulangan ke-1 hingga ke-4 dan mencapai efektivitas $100 \%$ sampai dua bulan berikutnya ( sampai ulangan ke-5), dan pada ulangan ke-6 mengalami penurunan menjadi $81,82 \%$. Rerata efektivitas dengan metode ulangan 2 bulan adalah $75,75 \%$.

Tabel 1. Kejadian dan kesembuhan trematodiasis menggunakan albendazol berdasarkan identifikasi telur cacing ulangan 2 bulan selama 12 bulan

\begin{tabular}{|c|c|c|c|c|c|c|}
\hline \multirow[t]{2}{*}{ No sapi } & \multicolumn{5}{|c|}{ Ulangan ke } & \multirow[b]{2}{*}{6} \\
\hline & 1 & 2 & 3 & 4 & 5 & \\
\hline 1 & F,P & $\mathrm{F}$ & $\mathrm{F}$ & negatif & negatif & negatif \\
\hline 2 & $\mathrm{~F}$ & negatif & negatif & negatif & negatif & negatif \\
\hline 3 & $\mathrm{P}$ & negatif & negatif & negatif & negatif & negatif \\
\hline 4 & $\mathrm{~F}, \mathrm{P}$ & $\mathrm{P}$ & $\mathrm{F}$ & negatif & negatif & negatif \\
\hline 5 & $\mathrm{~F}$ & $\mathrm{~F}$ & negatif & negatif & negatif & negatif \\
\hline 6 & $\mathrm{~F}$ & F,P & $\mathrm{F}$ & negatif & negatif & negatif \\
\hline 7 & $\mathrm{~F}$ & negatif & negatif & negatif & negatif & $\mathrm{F}$ \\
\hline 8 & $\mathrm{~F}$ & negatif & negatif & negatif & negatif & negatif \\
\hline 9 & $\mathrm{~F}$ & negatif & $\mathrm{F}$ & negatif & negatif & negatif \\
\hline 10 & $\mathrm{~F}$ & negatif & negatfi & negatif & negatif & negatif \\
\hline 11 & $\mathrm{~F}, \mathrm{P}$ & $\mathrm{F}$ & negatif & negatif & negatif & negatif \\
\hline 12 & $\mathrm{~F}$ & negatif & negatif & negatif & negatif & negatif \\
\hline 13 & $\mathrm{~F}$ & $\mathrm{~F}$ & $\mathrm{~F}$ & negatif & negatif & $\mathrm{F}$ \\
\hline 14 & F,P & negatif & negatif & negatif & negatif & F \\
\hline 15 & negatif & negatif & negatif & negatif & negatif & negatif \\
\hline 16 & negatif & negatif & $\mathrm{P}$ & negatif & negatif & negatif \\
\hline 17 & negatif & negatif & negatif & negatif & negatif & negatif \\
\hline 18 & negatif & F & negatif & negatif & negatif & negatif \\
\hline 19 & negatif & negatif & negatif & negatif & negatif & P \\
\hline 20 & negatif & negatif & negatif & negatif & negatif & negatif \\
\hline 21 & negatif & $\mathrm{F}$ & negatif & negatif & negatif & negatif \\
\hline 22 & negatif & negatif & negatif & negatif & negatif & negatif \\
\hline $\begin{array}{l}\text { Kejadian } \\
\text { cacingan }\end{array}$ & $63,63 \%$ & $36,37 \%$ & $27,27 \%$ & $0 \%$ & $0 \%$ & $18,18 \%$ \\
\hline Efektivitas & $36,36 \%$ & $63,63 \%$ & $72,73 \%$ & $100 \%$ & $100 \%$ & $81,82 \%$ \\
\hline $\begin{array}{c}\text { Rerata } \\
\text { efektivitas }\end{array}$ & $75,75 \%$ & & & & & \\
\hline
\end{tabular}

$\mathrm{F}=$ positif telur Fasciola sp., $\mathrm{P}=$ positif telur Paramphistomum $s p$. 
Felisitas et. al.

Tabel 2. Kejadian dan kesembuhan trematodiasis berdasarkan identifikasi telur cacing menggunakan albendazol ulangan 4 bulan selama 12 bulan

\begin{tabular}{|c|c|c|c|}
\hline \multirow[t]{2}{*}{ No. sapi } & \multicolumn{3}{|c|}{ Ulangan ke } \\
\hline & $\mathbf{1}$ & 2 & 3 \\
\hline $\mathbf{1}$ & $\mathrm{F}$ & $\mathrm{F}$ & $\mathrm{F}$ \\
\hline 2 & $\mathrm{~F}$ & negatif & negatif \\
\hline 3 & $\mathrm{~F}$ & negatif & $\mathrm{F}$ \\
\hline 4 & $\mathrm{~F}$ & negatif & negatif \\
\hline 5 & $\mathrm{~F}$ & negatif & negatif \\
\hline 6 & $\mathrm{~F}$ & F & $\mathrm{F}$ \\
\hline 7 & $\mathrm{~F}, \mathrm{P}$ & negatif & negatif \\
\hline 8 & $\mathrm{~F}$ & F & $\mathrm{F}$ \\
\hline 9 & $\mathrm{~F}$ & $\mathrm{~F}$ & $\mathrm{~F}$ \\
\hline 10 & F,P & negatif & negatif \\
\hline 11 & F,P & negatif & negatif \\
\hline 12 & negatif & F & negatif \\
\hline 13 & negatif & F & negatif \\
\hline 14 & negatif & negatif & $\mathrm{F}$ \\
\hline 15 & negatif & negatif & negatif \\
\hline 16 & negatif & negatif & $\mathrm{F}$ \\
\hline 17 & negatif & $\mathrm{F}$ & negatif \\
\hline 18 & negatif & negatif & negatif \\
\hline 19 & negatif & negatif & $\mathrm{F}$ \\
\hline Kejadian cacingan & $42,10 \%$ & $31,57 \%$ & $42,10 \%$ \\
\hline Efektivitas & $57,90 \%$ & $68,43 \%$ & $57,90 \%$ \\
\hline Rerata efektivitas & $61,41 \%$ & & \\
\hline
\end{tabular}

$\mathrm{F}=$ positif telur Fasciola $s p ., \mathrm{P}=$ positif telur Paramphistomum $s p$.

Tabel 3. Kejadian dan kesembuhan trematodiasis berdasarkan identifikasi telur cacing menggunakan albendazol dengan ulangan 6 bulan selama 12 bulan

\begin{tabular}{ccc}
\hline No sapi & Ulangan ke & $\mathbf{2}$ \\
\hline $\mathbf{1}$ & $\mathbf{1}$ & negatif \\
$\mathbf{2}$ & $\mathrm{F}$ & negatif \\
$\mathbf{3}$ & $\mathrm{F}$ & negatif \\
$\mathbf{4}$ & $\mathrm{F}$ & negatif \\
$\mathbf{5}$ & $\mathrm{F}$ & $\mathrm{F}$ \\
$\mathbf{6}$ & $\mathrm{F}$ & $\mathrm{F}, \mathrm{P}$ \\
$\mathbf{7}$ & $\mathrm{F}$ & negatif \\
$\mathbf{8}$ & negatif & $\mathrm{F}$ \\
$\mathbf{9}$ & negatif & negatif \\
$\mathbf{1 0}$ & negatif & negatif \\
$\mathbf{1 1}$ & negatif & $\mathrm{F}$ \\
& negatif & \\
Kejadian cacingan & & $36,36 \%$ \\
Efektivitas & $54,54 \%$ & $63,64 \%$ \\
Rerata efektivitas & $45,46 \%$ & \\
\hline
\end{tabular}

$\mathrm{F}=$ positif telur Fasciola $s p ., \mathrm{P}=$ positif telur Paramphistomum $s p$.

Pemberian albendazol dengan ulangan 4 bulan memberikan rerata efektivitas $61,41 \%$ dan ulangan 6 bulan dengan rerata paling kecil yaitu $54,55 \%$ (Tabel 2 dan 3 ).

Pengobatan pada ulangan pertama semua kelompok perlakuan umumnya memiliki efektivitas yang rendah dibandingkan ulangan selanjutnya, kecuali pada ulangan 4 bulan (Tabel 2) efektivitas obat pada ulangan 1 dan 3 sama $(57,90 \%)$. Hasil ini menunjukkan bahwa nilai 
efektivitas tertinggi albendazol untuk Fasciola sp. dan Paramphistomum sp. adalah dengan ulangan 2 bulan. Meskipun demikian, tingkat efektivitas albendazol selama pengobatan selama 12 bulan terlihat rendah karena hanya mampu menjaga populasi sapi dari infeksi cacing sebanyak 4 ekor (kelompok A), 2 ekor (kelompok B) dan 3 ekor (kelompok C) atau kurang dari 30\% setiap kelompok. Hasil ini menunjukkan tingkat efektivitas albendazol yang rendah untuk Fasciola sp. dan Paramphistomum sp. di wilayah Pakem, Sleman. Berdasarkan data ini, seharusnya mulai dilakukan usaha-usaha untuk mengatasi kejadian cacingan pada ternak dengan metode pengobatan yang tepat. Penelitian yang dilakukan oleh Shokier et al.(2013) menunjukkan efektivitas albendazol terhadap fasciolosis yang cenderung turun, dikarenakan efektivitas obat terbatas hanya pada stadium dewasa, dan kurang efektif untuk telur cacing. Senyawa antitrematoda (flukicides) dibedakan menjadi 3 golongan yaitu yang efektif untuk semua stadium juvenil dan dewasa, stadium juvenil umur 6-8 minggu dan dewasa, serta untuk stadium dewasa saja (Forbes et al., 2015). Mekanisme kerja albendazol yaitu berikatan pada beta tubulin pada sisi sensitif-colchicine pada dinding sel sehingga menghambat polimerisasi dan pembentukan tubulus cacing. Senyawa ini juga menghambat pembentukan spindel pada proses pembelahan sel, menyebabkan hambatan pembentukan dan perkembangan telur. Selanjutnya albendazol akan menghambat pengambilan glukosa oleh larva dan cacing dewasa sehingga terjadi deplesi penyimpanan glikogen (Plumb, 2011). Namun mekanisme resistensi oleh parasit menyebabkan terjadinya penghindaran target obat ataupun parasit mampu membangun mekanisme pertahanan yang spesifik. Gambar 1 menunjukkan bahwa semakin panjang periode pengulangan albendazol, maka prosentase kesembuhan dengan tidak ditemukannya telur pada feses semakin turun.

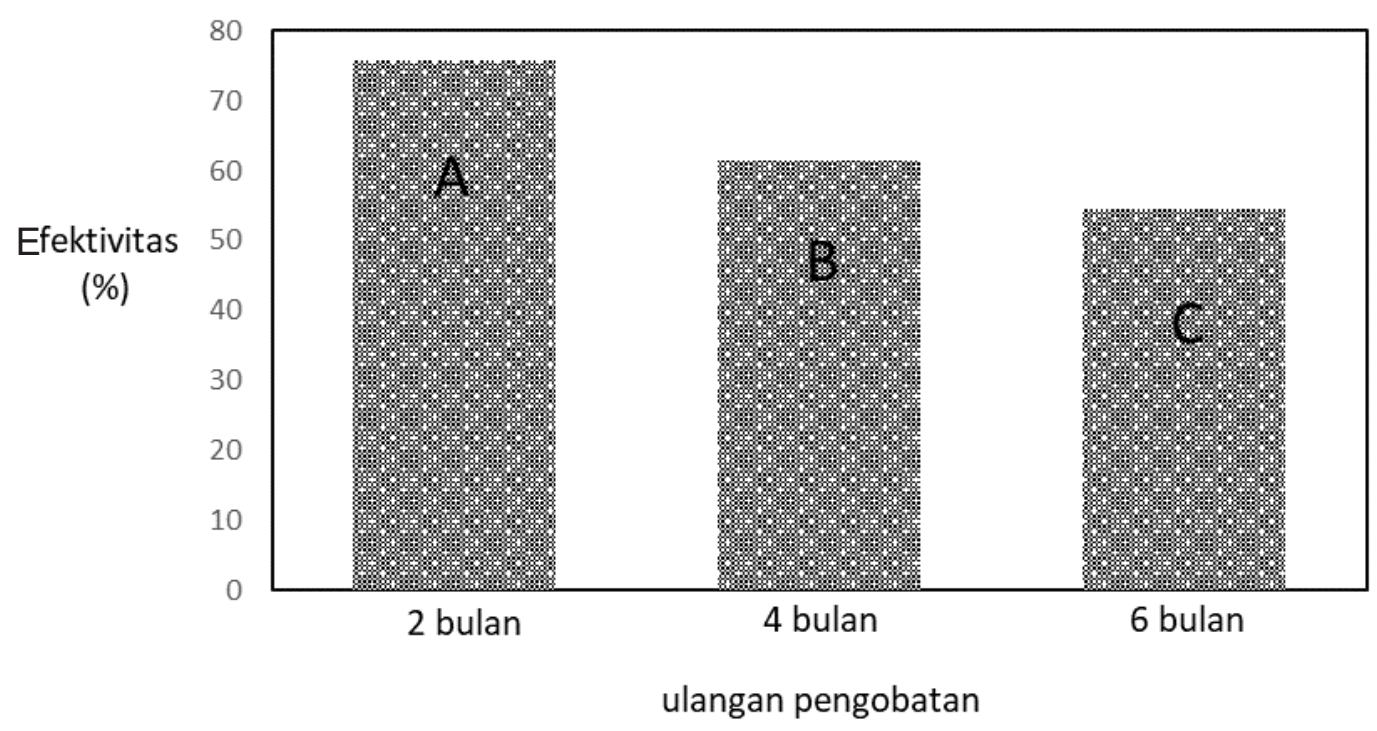

Gambar 2. Perbandingan efektivitas pengobatan cacingan dengan ulangan setiap 2 bulan (kelompok A), 4 bulan (kelompok B) dan 6 bulan (kelompok C) 
Felisitas et. al.

Prevalensi Fasciola sp. dan Paramphistomum $s p$. di dunia cukup tinggi dan keduanya merupakan jenis cacing trematoda yang sering dijumpai menginfeksi ternak di wilayah DIY. Penelitian yang dilakukan oleh Jones et al. (2017) melaporkan adanya pengobatan terhadap Fasciolosis merupakan prediktor ditemukannya juga infeksi Paramphistomum pada sapi, dan kemungkinan antara Fasciolosis dan Paramphistomum merupakan bentuk infeksi bersama (co-infections). Menurut berbagai sumber, pengobatan cacingan pada ternak di DIY sudah cukup lama menggunakan albendazol, karena alasan harganya ekonomis dan memiliki spektrum aktivitas yang luas untuk semua jenis cacing gastrointestinal pada ternak. Namun demikian menurut Alvarez-Sanchez (2006), penggunaan antelmintik untuk trematoda yang terbatas atau satu jenis saja yang digunakan berulang dalam jangka waktu lama tanpa melakukan evaluasi hasil pengobatan, memungkinkan terjadinya peningkatan populasi cacing resisten terhadap antelmintik. Dengan demikian perlu segera dilakukan strategi pengobatan yang tepat untuk mengurangi infeksi dan prevalensi cacing trematoda maupun cacingan pada ternak secara umum. Langkah tersebut dapat dilakukan melalui penggantian obat yang lebih efektif ataupun menggunakan kombinasi beberapa obat cacing untuk mencegah adanya multi resistensi cacing terhadap obat. Antelmintik golongan benzimidazol lain misalnya fenbendazol atau closantel yang memiliki mekanisme aksi berbeda dapat dicoba. Penggunaan kombinasi antelmintik dapat memperluas aktivitas terapi sehingga diharapkan efektivitas menjangkau pada semua stadium parasit. Trematoda memiliki hospes perantara sejenis siput air tawar, sehingga pemutusan siklus hidup parasit harus juga melibatkan agen mulosida serta kontrol sanitasi lingkungan. Kombinasi levamizol dengan oksiklozanid atau nitroxinyl pernah dicoba dan memberikan efektivitas yang baik terhadap trematoda (Mlekwa et al., 2017). Penelitian oleh Wirawan dkk. (2017) pada beberapa tanaman asli Indonesia menunjukkan efektivitas senyawa tanin kondensasi yang memiliki potensi vermisidal terhadap cacing gastrointestinal pada ruminansia. Herbal dan pengobatan alami perlu juga dicoba dan dikaji secara ilmiah untuk mengatasi masalah resistensi parasit. Evaluasi terapi terhadap penggunaan antimikroba, termasuk antelmintika, harus selalu dilakukan dalam periode tertentu untuk menjaga efektivitas dan mencegah terjadinya resistensi agen penyakit.

\section{Kesimpulan}

Terapi menggunakan albendazol dosis 10 $\mathrm{mg} / \mathrm{kg}$ berat badan pada kelompok sapi terinfeksi Fasciola sp. dan Paramphistomum sp. dengan selang waktu pemberian 2, 4 dan 6 bulan di Kecamatan Pakem, Kabupaten Sleman, Daerah Istimewa Yogyakarta menunjukkan efektivitas kurang dari 30\%. Perlu dilakukan evaluasi terapi dengan menggunakan jenis obat cacing lain atau kombinasi dengan obat lain.

\section{Ucapan Terima Kasih}

Penulis mengucapkan terima kasih yang sebesar besarnya kepada Kepala Dinas Pertanian, Pangan dan Perikanan Kabupaten Sleman, Kepala UPT Pelayanan Keswan, Pemerintah Kecamatan Pakem, Desa Harjobinangun dan Purwobinangun, Kelompok Ternak Turgorejo, Karanggeneng, Jamblangan, Blembem Lor dan Kaliwanglu atas semua bantuan material dan non material yang diberikan, sehingga penelitian dan artikel ini bisa terselesaikan.

\section{Daftar Pustaka}

Alvarez-Sanchez, M.M., Mainar- Jaime, R.C., PerezGarcia, J.,and Vasquez, F.A. (2006). Resistance of Fasciola hepatica to triclabendazole and 
albendazole in sheep in Spain. Veterinary Record.159:424-425

Cezar, A.S., Toscan, G., Camillo, G., Sangioni, L.A., Ribas, H.O., and Vogel, F.S.F.(2010) Multiple resistance of gastrointestinal nematodes to nine different skid drugs in the sheep flock in southern Brazil. Vet. Parasitol.173:157-160.

Colley, D.G., LoVerde, P.T., and Savioli, L. (2001). Medical helminthology in the 21 st century. Science .293:1437

De Graef, J., Claerebout. E., and Geldhof. P.(2013) Anthelmintic resistance of gastrointestinal nematodes cattle. Vlaams Diergeneeskd. Tijdschr. 2013;82:113-123.

Demeler, J., Van Zeveren, A.M., Kleinschmidt, N., Vercruysse, J., Höglund, J., Koopmann , R., Cabaret, J., Claerebout, E., Areskog, M., and von Samson-Himmelstjerna, G. (2009). Monitoring the efficacy of ivermectin and albendazole against gastrointestinal nematodes of intestinal cattle in Northern Europe. Vet. Parasitol.160:109-115.

Forbes, A.B., Reddick, D., and Stear, M.J.(2015). Efficacy of treatment of cattle for liver fluke at housing: influence of differences in flukicidal activity against juvenile Fasciola hepatica. Vet Rec.176(13):333

Jaeger, L.H. and Carvalho-Costa, F.A.(2017). Status of benzimidazole resistance in intestinal nematode populations of livestock in Brazil: a systematic review. BMC Veterinary Research 13:358

Jones, R.A., Brophy, P.M., Mitchell,E.S., and Williams, H.W.(2017). Rumen fluke (Calicophoron daubneyi) on Welsh farms: prevalence, risk factors and observations on coinfection with Fasciola hepatica. Parasitology. 144(2): 237-247.

Kaplan, R.M. (2001). Fasciola hepatica: a review of the economic impact in cattle and considerations for control. Vet.Therapeutics. 2(1):1-11.

Mlekwa, R.S.,Nzalawahe, J. and Kassuku, A.A.(2017). Prevalence of trematode infection in cattle and common flukecides used against flukes in Kilosa District, Tanzania. Tanzania Vet. Jour (abstract).32(1)
Parfitt, J.W. and Banks, A.W.(1970). A method for counting Fasciola eggs in cattle faeces in the field. Veterinary record. 87:180-182

Plumb, D. (2011). Albendazole. Plumb's Veterinary Drug Handbook. 7th ed. Wisconsin; Ames, Iowa. Willey. 19-21

Ramos, F., Portella, L.P., Rodriguez, F.D.S., Reginanto,C.Z., Cezar, A.S., Sanqioni, L.A., and Vogel, F.S.F. (2016). Anthelmintic resistance in gastrointestinal nematodes of beef cattle in the state of Rio Grande do Sul, Brazil. Int J Parasitol Drugs Drug Resist. 6(1): 93-101.

Regassa, F., Sori, T., Dhuguma, R., and Kiros., Y. (2006). Epidemiology of gastrointestinal parasites ofruminants in western Oroma, Ethiope. International Journal Applied Research of Veterinary Medicine. 4(1): 51-55

Shokier,K.M., Aboelhadid, S.M., and Waleed, M.A.(2013).Efficacy of five anthelmintics against a natural Fasciola species infection in cattle. Beni-Suef Univ Journal of Basic and Applied Sc.2:41-45

Waghorn, T.S., Leathwick, D.M., Rhodes, A.P., Jackson, R., Pomroy, W.E., West, D.M., and Moffat, J.R. (2006). Prevalence of anthelmintic resistance on 62 beef cattle farms in the North Island of New Zealand. N Z Vet J. 54 (6):278-82

Wirawan, I.G.K.O, Kurniasih, Prastowo, J. andNurcahyo, W.(2017). Daya vermisidal lima jenis etnofarmakologi terhadap cacing Haemonchus controtus secara in vivo. JSV.35(2):243-253.

World Health Organization. (2016).Model List of Essential Medicines (19th List). Archived (PDF). Retrieved Des.8.

Yazwinski, T.A., Tucker, C.A., Hornsby, J.A., Powell, J.G., Reynolds, J.L., Johnson, Z.B., Lindsey, W., and Silver, T.K.(2009) .Effectiveness evaluation of several cattle anthelmintics via the fecal egg count reduction test. Parasitol. Res. (105):71-76

Zahid, I.A., Latif, M. and Baloch, K.B. (2005). Incidence of endoparasites in exotic cattle calves. Pakistan Veterinary Journal .25(1): 4748. 